\title{
DESIGN AND CHARACTERIZATION OF NANOSPRAY WITH SELF-NANOEMULSIFYING DRUG DELIVERY SYSTEM USING SINERGISTIC COMBINATION OF MELASTOMA MALABATHRICUM L. FRACTION AND GENTAMICIN
}

\section{LIZA PRATIWI ${ }^{*}$, RAFIKA SARI ${ }^{2}$, PRATIWI APRIDAMAYANTI ${ }^{3}$}

\author{
1Pharmaceutical Technology Departement, Medical Faculty, Tanjungpura University, Pontianak, Indonesia, ${ }^{2}$ Pharmacy Biology \\ Departement, Medical Faculty, Tanjungpura University, Pontianak, Indonesia, ${ }^{3}$ Pharmacy Chemistry Departement, Medical Faculty, \\ Tanjungpura University, Pontianak, Indonesia \\ *Email: liza.pratiwi@pharm.untan.ac.id
}

Received: 24 Oct 2020, Revised and Accepted: 04 Feb 2021

\begin{abstract}
Objective: This study aimed to design a formula using Design-Expert software to obtain optimal Self-Nanoemulsifying Drug Delivery System (SNEDDS) formulas and to analyze nanospray characteristics of optimal SNEDDS.

Methods: The study began with preparing ethanol extract from Melastoma malabathricum. The extract was then fractionated using ethyl acetate. The formulation design stage began with a solubility test of Melastoma malabathricum fraction and gentamicin (MFG) in various surfactants, cosurfactants and oils. Furthermore, the 14 formula of SNEDDS with various compositions of the selected surfactants, co-surfactants and oils were formulated and evaluated with $\mathrm{pH}$ response and emulsification time. Analysis was carried out using Design-Expert software with the simplex lattice design method in order to obtain the optimal formula profile. The $\mathrm{pH}$, emulsification time, particle size, and zeta potential of the nanospray from SNEDDS optimal formulas were physically characterized. Stability of SNEDDS and the nanospray was then tested with freeze-thaw cycling and in vitro diffusion studies with Franz diffusion.
\end{abstract}

Results: Based on the study, the ratios of optimal formula SNEDDS composition of Tween 80, propylene glycol, and soybean oil were 2.69: 2.64: 1.67 parts. Nanospray with SNEDDS technology had characteristics of pH 5.61 \pm 0.16 , emulsification time $7.68 \pm 0.18$, particle size 270.7 nm, and zeta potential-37.20 $\mathrm{mV}$, and it was stable.

Conclusion: Nanospray can be formulated from optimal SNEDDS using Design-Expert software. Nanospray with SNEDDS technology has physical characteristics and is stable. In vitro diffusion studies revealed that the release of Melastoma malabathricum from nanospray was faster than that without preparation.

Keywords: Nanospray, SNEDDS, Melastoma malabathricum, Gentamicin

(C) 2021 The Authors. Published by Innovare Academic Sciences Pvt Ltd. This is an open access article under the CC BY license (https://creativecommons.org/licenses/by/4.0/) DOI: https://dx.doi.org/10.22159/ijap.2021v13i2.40094. Journal homepage: https://innovareacademics.in/journals/index.php/ijap

\section{INTRODUCTION}

Testing the effectiveness of antibiotic therapy given orally or topically to diabetes mellitus (DM) patients with complications of diabetic foot ulcers (DFU) was carried out on 24 patients with Wagner grade III and IV DFU. Four types of pathogenic bacteria were found to be resistant to the antibiotic gentamicin used topically or orally. One of the efforts to prevent and control the resistance was through the use of a combination of natural compounds that are potential to be antibacterial and antibiotics in a dosage form which is applicative and have been proven effective in DFU with bacterial infection. Medicinal preparations in the form of nanospray from SelfNanoemulsifying Drug Delivery System (SNEDDS), an optimum combination of Melastoma malabathricum fraction and gentamicin antibiotics (MFG), aimed to reduce the severity of further infections from DFU, and this could be an effective formula for controlling bacteria resistant to antibiotics. Melastoma malabathricum L. has significant activity as an antibacterial agent against Stapylococcus aureus and Escherichia coli bacteria. Sarbadhikary (2015) showed that the ethanol extract from this plant's leaf at a concentration of 50 $\mathrm{mg} / \mathrm{ml}$ produces the largest inhibition zone compared to other plants, namely $20 \mathrm{~mm}$ against Eschericia coli with moderate inhibitory response strength and $18 \mathrm{~mm}$ against Staphylococcus aureus bacteria with moderate inhibitory response strength [1]. This was due to the large content of phenol and flavonoid compounds which are the main components as antimicrobial agents [2]. Other chemical compounds that act as antibacterials in the ethanol extract from Melastoma malabathricum $L$ leaves included triterpenoids (asiatic acid, ursolic acid), quercetin, kaempferol, ellagic acid, tocopherols [3], glycosides, saponins, tannins, and alkaloids [4]. Other studies showed that the plant leaf extract of Melastoma malabathricum L. also has antibacterial activity against multidrug- resistant (MDR) Eschericia coli and methicillin-resistant Staphylococcus aureus (MRSA) [5].

The development of preparations with nanotechnology systems was for active substances with problems in solubility, lipophilicity, permeability, and the effects of degradation [6]. SNEDDS is an isotropic mixture of oil, surfactants and co-surfactants that will spontaneously form nanoemulsions when mixed with water through light agitation in the digestive tract. The nanoemulsion formed had a globule size $[7,8]$. In this study, spray bottle was used to generate a nanospray preparation from the nanoemulsion. SNEDDS solved the problem of BCS class II drugs with an emphasis on increasing solubility and bioavailability, enhancing pharmacodynamic potency, increasing drug release rate and drug dissolution, thus increasing therapeutic effectiveness $[9,10]$.

The purposes of this study were to design a formula using DesignExpert software to obtain optimal Self-Nanoemulsifying Drug Delivery System (SNEDDS) formulas, to analyze nanospray characteristics of optimal SNEDDS, and to analyze optimal SNEDDS and nanospray stability with freeze-thaw cycling method. The nanospray preparation referred to in this study was an applicative nanoemulsion preparation in spray form. The nanoemulsion was designed using SNEDDS. The optimal SNEDDS employed a combination of surfactant, co-surfactant, and oil designed using Design-Expert software with simplex lattice design method. SNEDDS could protect active compounds in Melastoma malabathricum leaf fraction and antibiotics so that the stability of the compounds was maintained. The $\mathrm{pH}$, emulsification time, particle size, and zeta potential of the nanospray from SNEDDS optimal formulas were physically characterized, and its stability was tested using freezethaw cycling and in vitro diffusion studies with Franz diffusion. 


\section{MATERIALS AND METHODS}

\section{Materials and excipients}

The equipment used in this study was analytical balance (Ohaus PA214, USA), glassware (pyrex), stopwatch, vortex mixer (Thermolyne), ultrasonicator (J. P. Selecta), UV-Vis spectrophotometer (Shimadzu tipe 2450), $1 \mathrm{~cm}$-sized quartz cuvette, a magnetic stirrer (Stuart CB162), pH meter (HANNA), filter paper, particle-size analyzer (Beckman coulter), micro pipette Socorex® $(0.5-10 ; 5-50 ; 50-200,200-1000 \mu \mathrm{l})$, Eppendorf tube, rotary evaporator (Heldolph tipe Hei-VAP), oven (Memmert), water bath (Memmert tipe WNB14), 120 mesh-sized sieve, aluminium foil, and thermometer. Melastoma malabathricum selected for the study were freshly from Sekajang village, Sanggau district, West Kalimantan, Indonesia. The excipients included ethanol 70\% (Dwicentra), nhexane (Merck), ethyl acetate (Merck), $\alpha$-mangostin (Sigma-Aldrich 98\%), methanol (Merck), virgin coconut oil (VCO) (Bagoes), Tween 80 (Bratachem), aquadest (Dwicentra), olive oil (bratachem), sun flower oil (Mazola), soybean oil, PEG 400 (Bratachem), propylene glycol (Bratachem), Tween 20 (Bratachem), Cremophor EL (SigmaAldrich), phosphate buffer (Bratachem), and Phyton molurus skin. The data analysis used IBM SPSS statistics program with one sample t-test.

\section{Preparation of Melastoma malabathricum leaf extract}

Melastoma malabathricum leaves were extracted by maceration using 96\% ethanol. Simplicia of the leaves that have been sieved with no. 40 mesh was put into a glass vessel, then poured and soaked with $96 \%$ ethanol until it was completely submerged. It was covered and left to stand for $24 \mathrm{~h}$ while being repeatedly shaken and macerated. Furthermore, the extracts of maceration mixed with the solvent were evaporated with a rotary evaporator to obtain a thick extract. The filtrates were then evaporated further on the hot plate. The remaining solvent was removed by placing the remaining residue in the desiccator containing silica or dryer for $24 \mathrm{~h}$.

Melastoma malabathricum fractions and gentamicin (MFG) solubility measurements in surfactants, Co-surfactants, and oils

A total of $10 \mathrm{mg}$ ethyl acetate fraction (EAF) of Melastoma malabathricum and $10 \mathrm{mg}$ gentamicin was added to $10 \mathrm{ml}$ soybean oil, VCO, olive oil, sunflower oil, Tween 20, Cremophor EL, Tween 80, PEG 400, and propylene glycol. This mixture was conditioned in a water bath at $40^{\circ} \mathrm{C}$ for $10 \mathrm{~min}$. The process of dissolving the fraction in a carrier was maximized by a sonicator for $15 \mathrm{~min}$ and left for two days at room temperature. After two days, insoluble part was separated by centrifugation at $3000 \mathrm{rpm}$ for $20 \mathrm{~min}$. The MFG samples that were more dissolvable were selected and used for subsequent optimization phase.

Orientation of surfactant, co-surfactant and oil composition formulations with simplex lattice design

Surfactants, co-surfactants and oils selected in previous study subsequently obtained 14 runs from Design Expert Software in various mixture compositions for the three components to be optimized, namely Tween 80 , propylene glycol, and soybean oil with a ratio of $3: 3: 1 ; 1.67: 1.67: 3.67 ; 1: 5: 1 ; 1: 3: 3 ; 5: 1: 1 ; 3: 1: 3 ; 3: 3$ : 1; 3.67: 1.67: 1.67; 1.67: 3.67: 1.67; 1: 1: 5; $5: 1: 1 ; 1: 5: 1 ; 1: 1: 5$; and 2.33: 2.33: 2.33 .

\section{Drug loading measurement}

Samples selected from Melastoma malabathricum $(5 \mathrm{mg}, 10 \mathrm{mg}, 15$ $\mathrm{mg}, 20 \mathrm{mg}, 25 \mathrm{mg}, 30 \mathrm{mg}, 50 \mathrm{mg}, 75 \mathrm{mg}, 100 \mathrm{mg}, 125 \mathrm{mg}$, and 150 $\mathrm{mg}$ ) were added to $5 \mathrm{ml}$ SNEDDS formulation. This referred to making a solid dispersion technique [14]. SNEDDS was then homogenized with a vortex for $5 \mathrm{~min}$, with a sonicator for $5 \mathrm{~min}$, and in a water bath at $45^{\circ} \mathrm{C}$ for $5 \mathrm{~min}$.

\section{Preparation of SNEDDS}

SNEDDS was made with a combination of Tween 80, propylene glycol and soybean oil. Then EAF was added. The mixture was conditioned in a water bath at $40{ }^{\circ} \mathrm{C}$ for $10 \mathrm{~min}$. The process of homogenizing the fraction in a carrier was maximized with a 1000 rpm vortex for $15 \mathrm{~min}$. Physical data from 14 SNEDDS runs could be used to determine the optimal formula. Determination of the optimal formula was done by simplex lattice design method using DesignExpert $®$ version 7.0.0 software. Characteristics of the physical properties used in determining the optimal formula were emulsification time and $\mathrm{pH}$ [15].

\section{Measurement of $\mathrm{pH}$}

Emulsion $\mathrm{pH}$ measurement was done by dipping the electrode of the $\mathrm{pH}$ meter into the emulsion. SNEDDS $(100 \mu \mathrm{l})$ were added with distilled water up to $5 \mathrm{ml}$. The mixture was homogenized by flipping for $1 \mathrm{~min}$. The reading on the $\mathrm{pH}$ meter was done after $5 \mathrm{~min}$ to make sure the number is stable and does not move anymore [15].

\section{Measurement of emulsification time}

Distilled water $(500 \mathrm{ml})$ was conditioned on a magnetic stirer with a speed of $120 \mathrm{rpm}$. A total of $1 \mathrm{ml}$ SNEDDS of the EAF of Melastoma malabathricum was quickly dripped into the media [14].

\section{Preparation of optimum formulation of MFG loaded S-SNEDDS}

Optimal SNEDDS was obtained through assigning values and weights to responses, namely $\mathrm{pH}$ and emulsification time to obtain optimal desirability and contour plot formula values. Furthermore, the verification between the optimal SNEDDS prediction software and the optimal SNEDDS was carried out. The optimum SNEDDS was made with a combination of surfactants, co-surfactants and selected oils with comparisons according to the software analysis. Furthermore, ethyl acetate and gentamicin fractions were added. The mixture was conditioned in a water bath at $40^{\circ} \mathrm{C}$ for $10 \mathrm{~min}$. The process of dissolving the fraction in the carrier was maximized using a sonicator for $15 \mathrm{~min}$.

\section{Nanospray preparation}

Total of $1 \mathrm{ml}$ SNEDDS was mixed with distilled water up to $5 \mathrm{ml}$ and was homogenized by flipping for $1 \mathrm{~min}$. This formed a nanoemulsion which was then put into a spray container.

\section{Characterization of MFG loaded nanospray}

\section{pH measurement of nanospray}

Emulsion $\mathrm{pH}$ measurement was done by dipping the electrode of the $\mathrm{pH}$ meter into the emulsion. SNEDDS $(100 \mu \mathrm{l})$ were added with distilled water up to $5 \mathrm{ml}$. The mixture was homogenized by flipping for $1 \mathrm{~min}$. The reading on the $\mathrm{pH}$ meter was done after 5 min to make sure the fig. is stable and does not move anymore.

\section{Emulsification time measurement of nanospray}

Distilled water $(500 \mathrm{ml})$ was conditioned on a magnetic stirer with a speed of $120 \mathrm{rpm}$. A total of $1 \mathrm{ml}$ SNEDDS of the EAF of Melastoma malabathricum was quickly dripped into the media [14].

\section{Particle size and zeta potential observation of nanospray}

Total of $1 \mathrm{ml} \mathrm{SNEDDS} \mathrm{was} \mathrm{mixed} \mathrm{with} \mathrm{distilled} \mathrm{water} \mathrm{up} \mathrm{to} 5 \mathrm{ml}$ and was homogenized by flipping for $1 \mathrm{~min}$. After that, $3 \mathrm{ml}$ of it was taken and put into a cuvette for analysis. Particle size data obtained as an output on a computer were the average particle size, particle size distribution, and the deviation from the mean.

\section{Physical stability evaluation \\ Centrifugation evaluation}

The test used centrifugation at $5000 \mathrm{rpm}$ for $30 \mathrm{~min}$. Then observations were made on the preparation of instability parameters such as separation, deposition, creaming, and cracking. Stable preparations were subjected to further testing, namely the heating and cooling test [16].

\section{Heating and cooling}

In this test, six cycles were carried out using a temperature of $4{ }^{\circ} \mathrm{C}$ and $40{ }^{\circ} \mathrm{C}$ with a storage time of $48 \mathrm{~h}$. Formulations that did not experience instability parameters such as separation, deposition, creaming or cracking were subjected to further testing, namely the freeze thaw test [16]. 


\section{Freeze thawing}

Six cycles of freezing and thawing were administered at temperatures between- $21^{\circ} \mathrm{C}$ and $25^{\circ} \mathrm{C}$ with a storage time of $48 \mathrm{~h}$. After centrifugation at a speed of $5000 \mathrm{rpm}$ for $5 \mathrm{~min}$, observations of instability parameters such as separation, deposition, creaming, and cracking were carried out [16].

\section{In vitro penetration study}

The diffusion test was carried out in vitro using Franz diffusion cells and phosphate buffer $\mathrm{pH} 7.4$ as receptor compartments.

\section{Quercetin standard curve}

The standard concentration of Melastoma malabathricum was 14 $\mu \mathrm{g} / \mathrm{ml}$ to $49 \mu \mathrm{g} / \mathrm{ml}$. This solution was used to determine the maximum wavelength of Melastoma malabathricum leaves in the 400-450 $\mathrm{nm}$ wavelength range. The standard standard curve of quercetin was obtained as a result of linear regression of concentration versus absorbance.

\section{Analysis of the amount of quercetin transported by franz} diffusion

The membrane used was a shed snake skin from Phyton molurus. The receptor compartment was filled with $20 \mathrm{ml}$ phosphate buffer $\mathrm{pH} 7.4$, and it was kept at $37^{\circ} \mathrm{C}$. The shed snake skin membrane was placed between the donor compartment and the receptor compartment with the stratum corneum facing up. The $200 \mathrm{mg}$ preparations was placed on the membrane of the shed snake skin. Samples were taken at $0,5,1,2,3,4,5,6,7,8 \mathrm{~h}$. Those were taken as much as $5 \mathrm{ml}$ from the receptor compartment using a micropipette and replaced with the same volume of $5 \mathrm{ml}$ phosphate buffer. Samples were measured for their absorption at the maximum wavelength with a UV-Vis spectrophotometer.

\section{Data analysis}

The analysis results included test results of $\mathrm{pH}$ and emulsification time SNEDDS of MFG. The results of the $\mathrm{pH}$ and emulsification time of the optimum SNEDDS formula were obtained and analyzed with the prediction of the optimum formula test results using simplex lattice design method. Data were analyzed using IMB SPSS Statistics program with a one sample t-test.

\section{RESULTS AND DISCUSSION}

\section{Solubility test results of $\mathrm{mfg}$ in oils, surfactants, co-surfactants}

The combination of MFG was dissolved in various surfactants (Tween 80, Tween 20, Cremophor EL), co-surfactants (propylene glycol, PEG 400), and oils (soybean oil, VCO, olive oil, sunflower oil). This mixture was then left for two days at room temperature. After two days, the insoluble portions were separated by centrifugation at $3000 \mathrm{rpm}$ for $20 \mathrm{~min}$. Tween 80 was chosen because it is a non-toxic surfactant widely used in food and pharmaceuticals. Tween 80 caused spontaneous emulsification and forms a gel in the oil-water interface layer. The stabilization mechanism was by reducing the interface stress in a relatively short time. Tween 80 was an amphiphilic molecule when added to the oil/water mixture; the hydrophilic head accommodated into the water phase and the hydrophobic tail was to the oil phase. Subsequently, there was a reduction in interfacial tension, and the possibility of splitting in the oil/water phase was small.

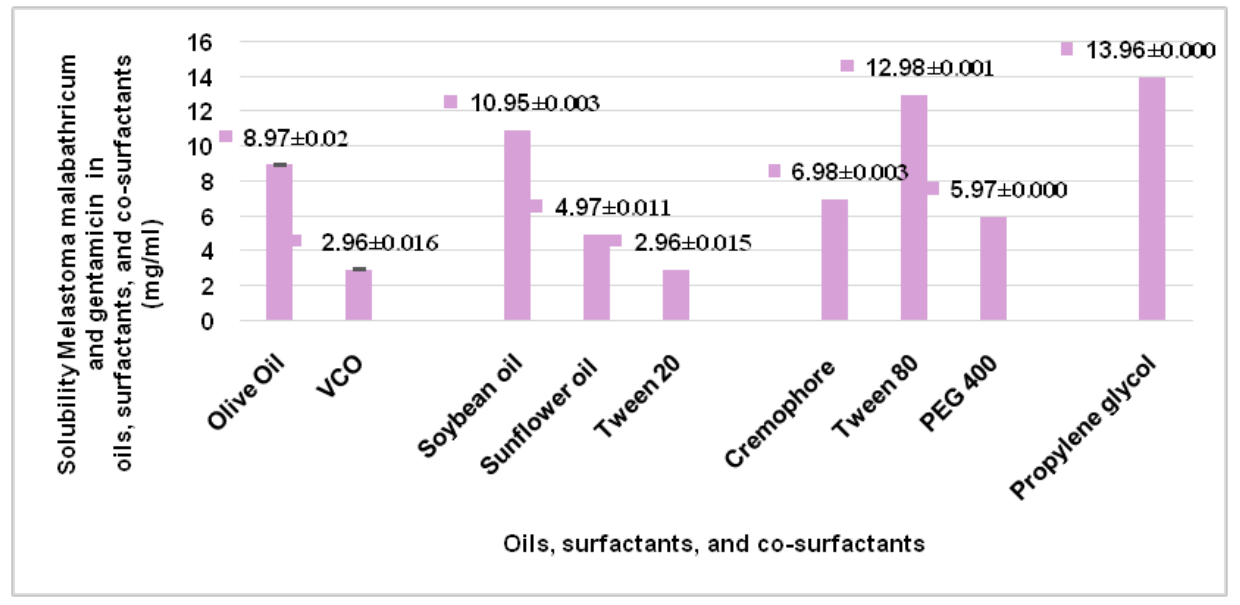

Fig. 1: Result of the solubility test of $\mathrm{mfg}$ in oils, surfactants, and co-surfactants $(n=3, \operatorname{mean} \pm S D)$

\section{Determination of MFG content on SNEDDS}

Based on the results of MFG, a concentration of $50 \mathrm{mg} / 5 \mathrm{ml}$ SNEDDS was used because the concentration of $75 \mathrm{mg} / 5 \mathrm{ml}$ on SNEDDS showed that the system was unable to dissolve the fraction. This was indicated by the presence of sediment on three days of observation.

\section{Orientation SNEDDS formula of MFG}

The orientation of the SNEDDS formula was carried out to find out the comparison of SNEDDS and carriers that can produce SNEDDS with Tween 80, propylene glycol, and soybean oil. The responses of $\mathrm{pH}$ test responses and emulsification tests obtained are presented in fig. 2 and 3.

The ability of surfactants to dissolve compounds was affected by interface stress. Surfactants worked by reducing the interface tension between the oil phase and the water phase after the SNEDDS preconcentrate was dispersed in the dispersing medium, thus forming a nanoemulsion. The type and amount of surfactants would affect the size of the oil droplets in the water phase [6].

\section{Construction of ternary phase diagram pH response}

Based on the test results, all the runs had a $\mathrm{pH}$ range permitted for use on the skin. The test aimed to determine the safety of the preparation, especially when used on the skin. A too low $\mathrm{pH}$ causes irritation, while a too high $\mathrm{pH}$ results in scaly skin. The $\mathrm{pH}$ range of topical preparations was 4.5-6.5 [17]. Based on the normal curve of the plot of residuals, the data spreaded around the diagonal line and followed the direction of the diagonal line. This shows that the linear model is sufficiently good to explain the effect of material interactions on $\mathrm{pH}$ (table 1).

Table 1: ANOVA test on pH Response (Design expert ${ }^{\circledR}$ Ver. 7.0.0.)

\begin{tabular}{lll}
\hline Source & P-value Prob $>\mathbf{F}$ & Result \\
\hline Model-linear & 0.00 & Significant \\
Lack of fit & 0.57 & Not Significant \\
\hline
\end{tabular}


The analysis results of the lack of fit indicated that the p-value was $>0.05$ at the $95 \%$ significance level. This shows that there is no significant difference between the experimental data and the predicted data from the proposed model. The linear model had a pvalue $<0.05$ which indicates a significant difference in $\mathrm{pH}$ from the use of different oil, surfactant, and co-surfactant phases.
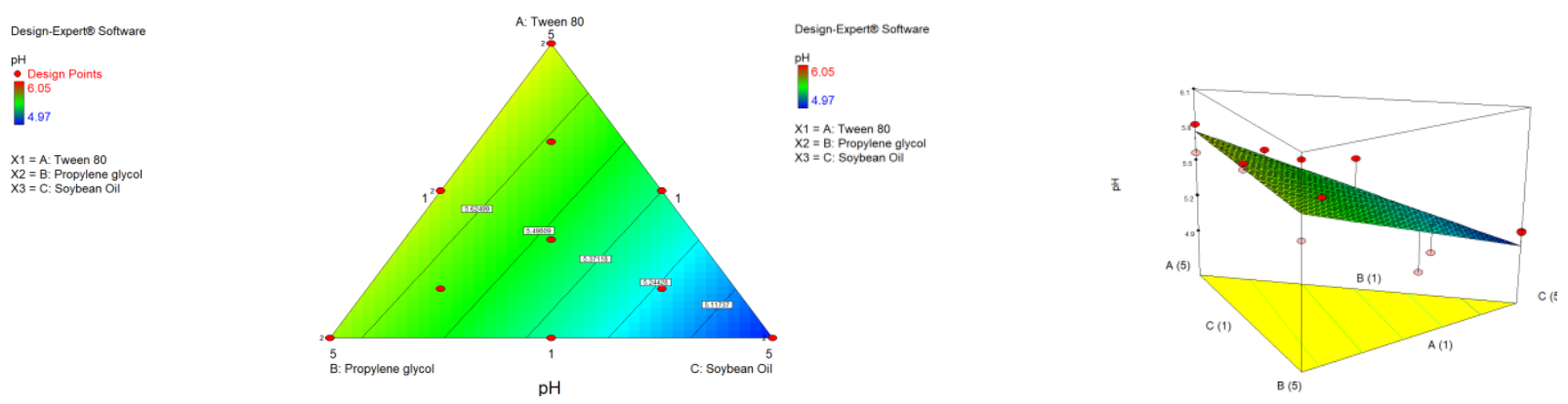

Fig. 2: Contour Plot of pH response: X1 = A: Tween 80, X2 = B: propylene glycol, X3 = C: Soybean Oil (Design expert $®$ Ver. 7.0.0.)

Fig. 2 shows the $\mathrm{pH}$ response contour plot. Based on the data from $\mathrm{pH}$ response and reflectance contour plot, the equation of simplex lattice design is:

$\mathrm{Y}=0.85(\mathrm{~A})+0.83(\mathrm{~B})+0.66(\mathrm{C})$

$\mathrm{Y}=\mathrm{pH}, \mathrm{A}$ : Tween 80, B: Propylene glycol, C: Soybean Oil.

The blue contour plot shows the smallest $\mathrm{pH}$ value followed by green which indicates the greatest $\mathrm{pH}$. The green area is influenced by the increase in Tween 80 . This shows that Tween 80 had a role in increasing the $\mathrm{pH}$ value in SNEDDS preparations. The coefficient values of Tween 80 , propylene glycol and soybean oil are positive, meaning that each component making up SNEDDS was able to increase the $\mathrm{pH}$ response. Based on the coefficient values, Tween 80 has the highest $\mathrm{pH}$ value.

\section{Emulsification time test}

The special cubic model had a p-value $<0.05$ which indicates a significant difference in emulsification time from the use of different compositions of the oil, surfactant, and co-surfactant phases. This result is reinforced by the lack of fit value $>0.05$ which indicates that there is no significant difference between the observation results and the predicted data from the model made (table 2).

Table 2: ANOVA test on emulsification time response (Design Expert ${ }^{\circledR}$ Ver. 7.0.0.)

\begin{tabular}{lll}
\hline Source & P-value prob $>\mathbf{F}$ & Result \\
\hline Model-special cubic & 0.00 & Significant \\
Lack of fit & 0.08 & Not significant \\
\hline
\end{tabular}

Fig. 3 shows the results of the emulsification time test. Measurement of emulsification time on 14 SNEDDS runs was able to form nanoemulsions in aquadest media at various times. This result is reinforced by the lack of fit value $>0.05$ which indicates that there is no significant difference between the observation results and the predicted data from the model made.
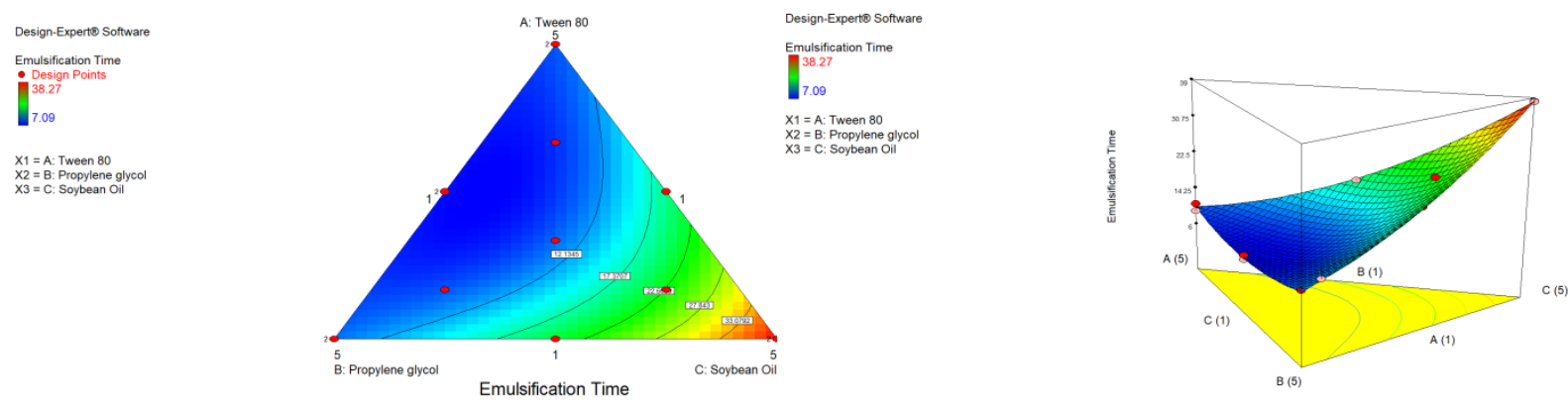

Fig. 3: Contour plot of emulsification time response (Design Expert ${ }^{\circledR}$ Ver. 7.0.0.)

Fig. 3 shows a normal curve for the plot of residuals emulsification time. Based on the data of $\mathrm{pH}$ response and reflectance contour plot, the equation of simplex lattice design is:

$$
\begin{aligned}
& Y=0.47 \quad(\mathrm{~A})+0.31 \quad(\mathrm{~B})+7.74 \quad(\mathrm{C})+0.98 \quad(\mathrm{~A})(\mathrm{B})+0.48 \quad(\mathrm{~A})(\mathrm{C})+0.79 \\
& (\mathrm{~B})(\mathrm{C})-1.71(\mathrm{~A})(\mathrm{B})(\mathrm{C}) .
\end{aligned}
$$

$\mathrm{Y}=$ emulsification time, A: Tween 80, B: Propylene glycol, C: Soybean Oil.

Propylene glycol as cosurfactant had a major influence on emulsification time. Mustika et al. (2019) showed that the dispersion ability of propylene glycol $\pm 15 \mathrm{~s}$ was included in category A [18], capable to produce a nanoemulsion quickly in about 1 min [19] with a clear nanoemulsion display. This is in accordance with the results obtained in this study. The spontaneous formation of nanoemulsions is one of the important parameters in the SNEDDS formulation. Nanoemulsion is expected to form quickly when in water. The determination of the emulsification time was carried out to obtain an overview of the ease with which SNEDDS can form emulsions. Fig. 4 shows the contour plot of the emulsification time response. The coefficient values of Tween 80-propylene glycol, Tween 80propylene glycol, as well as propylene glycol with soybean oil were positive, meaning that the combination of components could increase the emulsification time response. The coefficient value of Tween 80, propylene glycol, and soybean oil had a positive value, meaning that the combination of these three mixtures could increase the emulsification time value. The value of soybean oil coefficient was greater than that of Tween 80 , and the coefficient of Tween 80 is greater than the coefficient of propylene glycol. Based on the coefficient value, the interaction between Tween 80 and propylene glycol increased the emulsification time value greater because the coefficient was higher than that of propylene glycol and soybean oil and than the interaction between propylene glycol and soybean oil. 
The interaction of the three components in SNEDDS, namely Tween 80 , propylene glycol and soybean oil decreased the emulsification time value. This made the emulsification time on the composition of the three components in SNEDDS accelerate the emulsification time. The more Soybean Oil was used, the longer the emulsification time was. The short emulsification time was mediated by the action of surfactants and cosurfactants which were able to immediately form the oil interface layer. Cosurfactants played more important role in emulsification time and non-droplet size reduction. They slipped and formed an empty space between the surfactant and increase the fluidity, so that they could form nanoemulsion faster. This shows that propylene glycol as cosurfactant had a role in accelerating the emulsification time. The emulsification enhancement ability of the cosurfactant was determined by the length of the hydrophobic alkyl chain. The longer the chain was, the better the emulsification ability would be obtained [20].

The oil component could increase the emulsification time of nanoemulsion. Zhao et al. (2010) stated that the addition of ethyl oleate to SNEDDS could increase the emulsification time even though the particle size became smaller with increasing surfactant concentration [9]. Increasing the concentration of oil could slow down the emulsification time because of smaller concentrations of surfactants and cosurfactants, so they could not form emulsions in a short time [21, 22]. Short emulsification time was influenced by small oil concentrations and high cosurfactant concentrations, so that the viscosity was smaller [23]. Based on fig. 4 on the contour plot, the blue color shows the smallest emulsification time value followed by green, yellow, and red. The red color shows the greatest emulsification time. This red area is affected by an increase in soybean oil. The blue areas are affected by Tween 80 and Propylene glycol. The lower the emulsification time was, the better and faster nanoemulsions in distilled water media were formed.

\section{Optimization of MFG loaded S-SNEDDS}

The $\mathrm{pH}$ was in the range 4.5-6.5 [17]. The minimum emulsification time was $2-20$ seconds because the emulsification time was less than 60 seconds fulfilling the grade a requirements [24]. The optimal formula result obtained from the simplex lattice design was a formula with a ratio of Tween 80: propylene glycol: soybean oil (4.98: 1.02: 1 ) with a desirability value of 0.80 . The desirability value indicated that the response variable chosen for formula optimization could reach the optimal point according to the desired target. Fig. 4 shows the relationship between the components (Tween 80, propylene glycol, and soybean oil) and the active substances of the MFG on the desirability value.
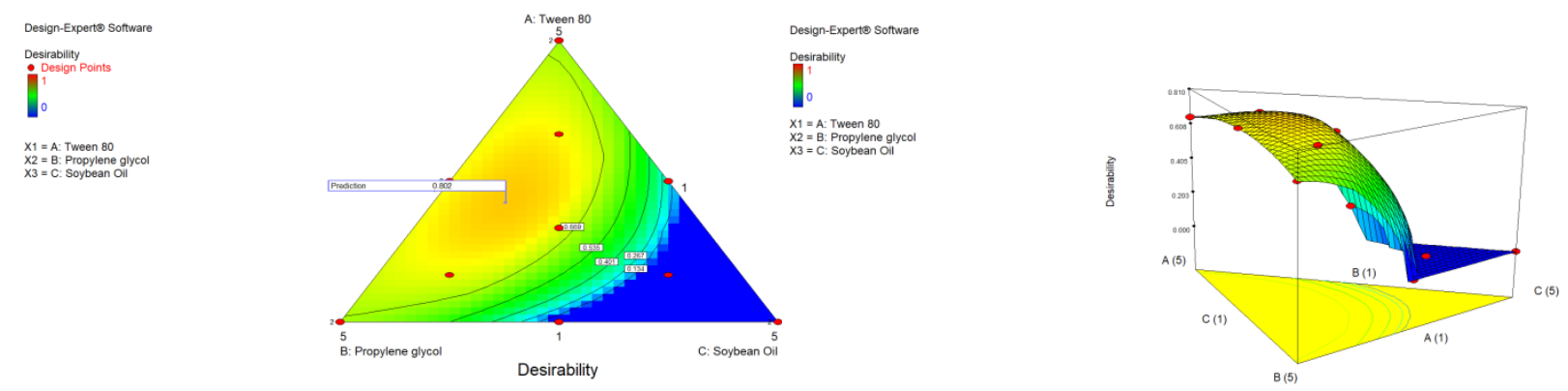

Fig. 4: Desirability SNEDDS MFG (Design expert@ Ver. 7.0.0.)

\section{Optimal formulation of SNEDDS}

The optimal formula composition based on the analysis resulted in a comparison of Tween 80: propylene glycol: soybean oil with a composition of 2.69: 2.64: 1.67 parts. Based on the optimal formula produced by the simplex lattice design in the Design-Expert software, it was predicted that the formula could produce $\mathrm{pH} 5.59$ and an emulsification time of 7.34 seconds.

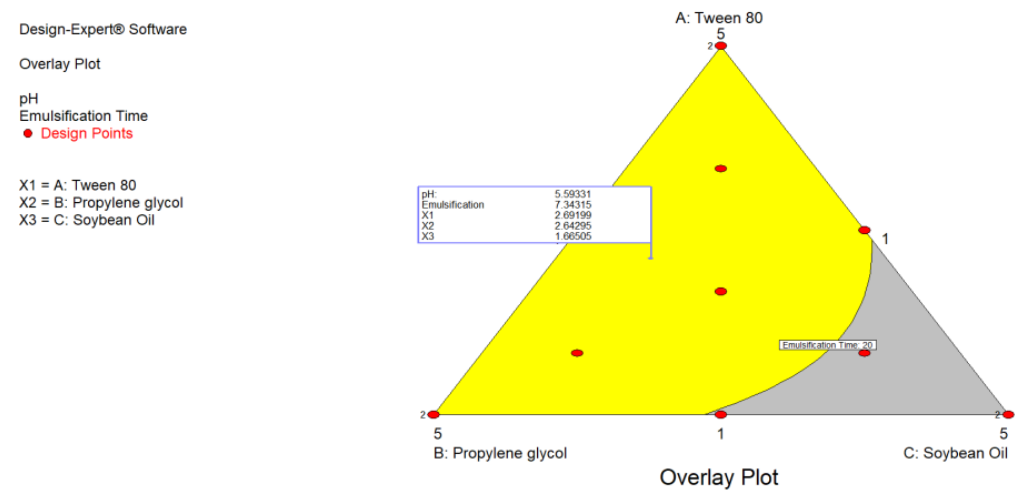

Fig. 5: Superimposed optimal SNEDDS formula combination Melastoma malabathricum fraction and gentamicin (Design expert@ Ver. 7.0.0.)

Based on fig. 5, superimposed contour plot of pH response and emulsification time is generated. The resulting superimposed resulted in a yellow area giving optimal response. This area provides a prediction of the optimal formula with a desirability of 0.802 . The optimal formula composition based on the analysis obtained, a comparison of Tween 80: propylene glycol: soybean oil was with a composition of 2.69: 2.64: 1.67 parts.

According to Shafiq-un-Nabi et al. (2007), the solubility of drugs in oil in nanoemulsions was the most important component because it was related to the ability of nanoemulsions to keep drugs in a dissolved form which is strongly influenced by the solubility of drugs in the oil phase. The amount of oil used in this optimization was one part of the total surfactant-co-surfactant-oil composition. If the oil composition was increased, the interaction balance was not achieved, resulting in an inhomogeneous phase (separation) [25]. The bond between VCO and Tween 80 occurred because of the oleic acid contained in Tween 80. Oleic acid has an XlogP of 6.5 so that it easily binds with other compounds that are lipophilic. Compounds 
with $\log \mathrm{P}>4$ were included into highly lipophilic compound category [26].

The optimal SNEDDS formula composition of Tween 80, propylene glycol, and soybean oil shows that the composition of Tween 80 as a surfactant is only able to form a homogeneous mixture if the composition ratio is greater than that of propylene glycol as a cosurfactant. The surfactant-cosurfactant interactions occurred due to the presence of a hydrophilic part (hydroxy group) in the compound. The higher the amount of surfactant in the ratio was, the better the interaction balance was achieved. Conversely, if the amount of cosurfactant increased, the interaction balance was not achieved, so that an inhomogeneous phase was formed (separating).

\section{Verification of optimal SNEDDS formula combination of MFG}

The verification was done by making optimal SNEDDS of experimental results that were compared with predictive software. Table 3 shows the results of verification of the optimal formula.

Table 3: Verification of optimal SNEDDS formula combination of the Melastoma malabathricum fraction and gentamicin (Design expert ${ }^{\circledR}$ Ver. 7.0.0.)

\begin{tabular}{llll}
\hline No & Sample & pH & Emulsification time (s) \\
\hline 1 & Optimal SNEDDS prediction & 5.59 & 7.34 \\
2 & Optimal SNEDDS optimal experimental results & $5.61 \pm 0.16$ & $7.68 \pm 0.18$ \\
\hline
\end{tabular}

${ }^{*}$ Values are expressed as mean $\pm \mathrm{SD}, \mathrm{n}=3$ (number 2 )

Based on the probability value of each response, showing that the obtained p-value is greater than 0.05 , there is no significant difference between the predicted results of the simplex lattice design on the Design-Expert software and the results of experimental observations. The SNEDDS observation results were compared with the results of the predictive response produced by the optimal formula in the simplex lattice design. Verification was then carried out using one sample t-test in Open Stat software. The SPSS data analysis applied one sample t-test. The $\mathrm{pH}$ test parameter generated $p$-value $0.85>0.05$ so that there is no difference between the predictions from the Design-Expert software with the simplex lattice design method and the experimental results on the optimal SNEDDS formula. In the emulsification time test, p-value was $0.080>0.05$ means that there is no significant difference between the predictions of the software and the experimental results. SNEDDS could increase the spread, stability, and bioavailability of plant extracts.

SNEDDS formulation was prepared using Tween-80 as a surfactant. The optimized design showed results that met the requirements of the SNEDDS test, and the in vitro antioxidant and antidiabetic activity of the SNEDDS was observed to be comparable to that of ascorbic acid and acarbose [27]. Another research showed that SNEDDS formulation was optimized with a simplex lattice design. The solubility study showed the highest solubility. A pseudo ternary phase diagram was created to identify efficient self-emulsification regions. In vitro diffusion studies revealed that the release of calcium rosuvastatin from SNEDDS was faster [28].

\begin{abstract}
MFG nanospray
Nanospray was formulated by adding the optimal SNEDDS formula to water and then was packed in a spray container. Fig. 7 shows the nanospray from optimal formula SNEDDS. In this study, a nanoemulsion designed with the self-nanoemulsifiying drug delivery system (SNEDDS) was used for the nanospray. SNEDDS was allowed for large-scale manufacturing as it could be done easily and the manufacturing process was economical, so that it became attractive in industry, and it was thermodynamically stable, making it easier for storage [29]. In another study, SNEDDS was able to overcome the problem of irritation and olmesartan which had poor solubility which would affect the bioavailability of the drug [30].

In the development of nanospray formulations, surfactants that were highly localized to the emulsion droplet surface reduced interfacial free energy and provided a mechanical barrier to coalescence resulting in thermo mechanical spontaneous dispersion [31]. Furthermore, co-surfactants increased the interface fluidity by penetrating into the surfactant film which created a vacuum between the surfactant molecules [32]. After being added with water, the formed nanoemulsion was not cloudy and had a yellowish color which indicates spontaneous nanoemulsion formation [33].
\end{abstract}

Observation of the size and size distribution of nanospray droplets combined with MFG

The nanospray droplet size observations were carried out to ascertain the $\mathrm{nm}$ size of the nanospray droplets. Fig. 6 shows the particle size distribution.

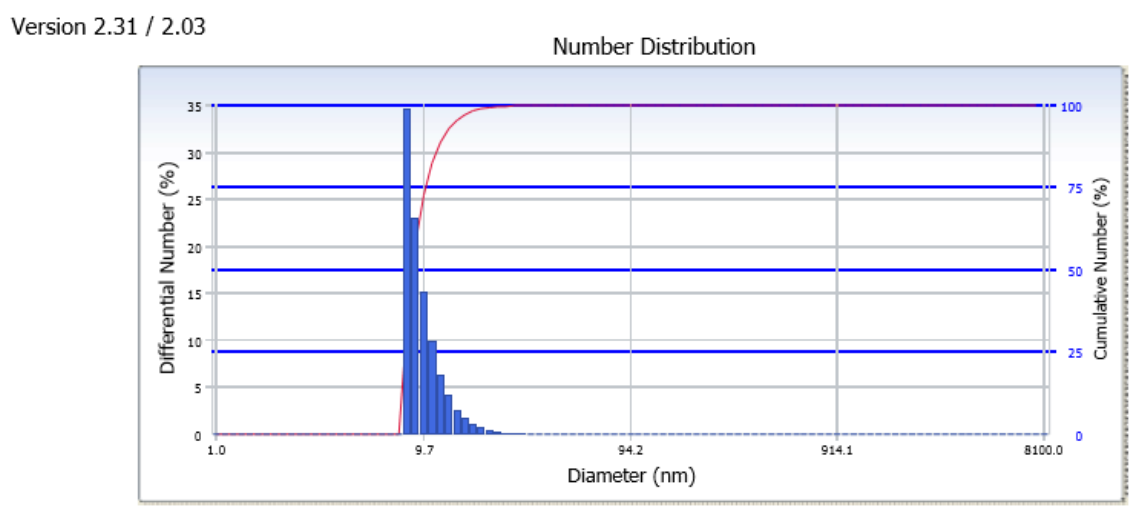

Fig. 6: Observation of the size and size distribution of nanospray droplets combined with Melastoma malabathricum fraction and gentamicin

Based on the test results, the average size of the nanospray was 270 $\mathrm{nm}$, less than $300 \mathrm{~nm}$. This proves that the SNEDDS preparations made are capable to preparation nanospray, which is in the nanometer range [34]. The droplet size decreased due to the increase in surfactant concentration [35]. The higher the surfactant ratio compared to the cosurfactant was, the smaller the 
nanoemulsion size was obtained [36]. Surfactants could cause a decrease in the interface film and stabilized it, resulting in a small droplet diameter, while the addition of co-surfactants could cause a wider interface film $[37,38]$. The relative proportions of surfactants and cosurfactants caused variation in droplet size [39].

The particle size of the nanospray was also influenced by the composition of the oil [40]. Oil was able to increase the ability of SNEDDS to carry drugs, but it maked the size of the nanospray larger, so that the ratio of the oil ratio used was always smaller than that of surfactants [41]. Nanoemulsion droplet size could regulate effective drug release [20,39, 42]. In another study, an average droplet size of $227.5 \pm 0.42 \mathrm{~nm}$ was obtained [43], self-emulsifying drug delivery systems yielded nanoemulsion with a globule size range of $504.4 \mathrm{~nm}$ [34]. This is related to the relative increase in the proportion of surfactants in oil droplet stabilization as a result of localization of surfactant molecules at the oil-water interface [20, 44]. The small droplet size of the SNEDDS formula was due to the reduction in surface tension led by the presence of surfactants and cosurfactants [45]. The SNEDDS droplet size also increased due to the content of the active substance. In the SNEDDS ceftriaxone study, the particle size increased with the increasing concentration of ceftriaxone sodium [46]. In this study, two active compounds, MFG were used. The PI (polydispersity index) value states the homogeneity of the nanospray particles. The PI value obtained from testing with aquadest media was 0.685 . The PI value varied from 0.0 to 1.0 , and the closer to 0 was, the more homogeneous the particles were [47]. A polydispersity index (PDI) of less than 0.5 indicated a uniform globule size distribution $[48,49]$, so that the nanoemulsion particle size distribution was uniform, and the method of making nanoemulsions had good reliability.

Observation of zeta potential of nanospray droplets in combination with MFG

Fig. 7 shows the results of zeta potential determination.

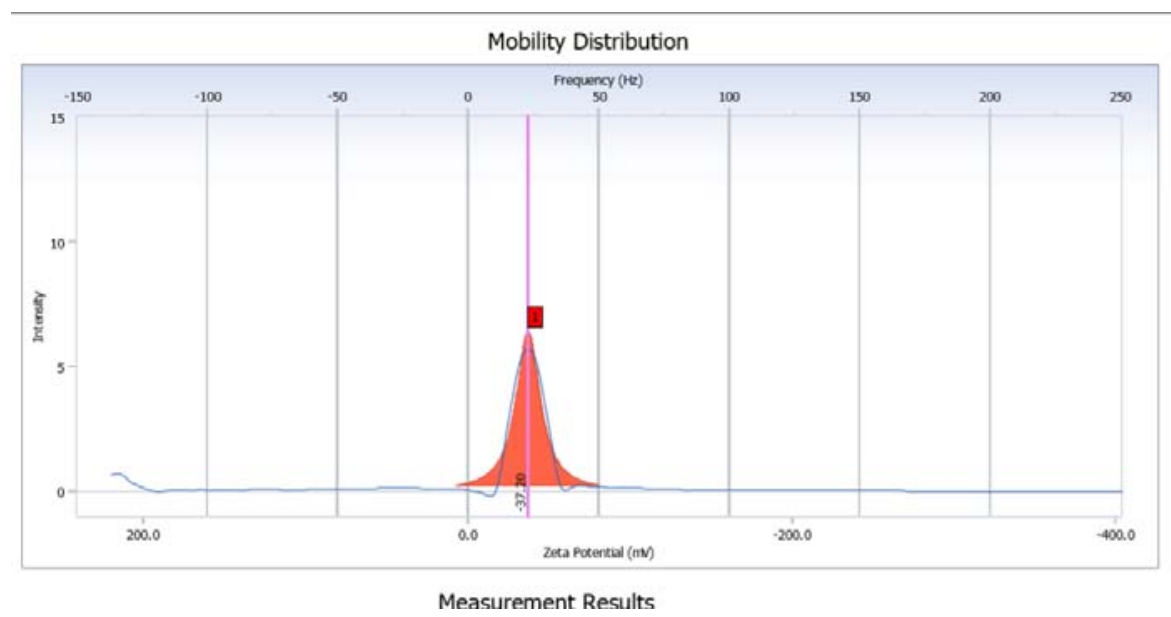

Fig. 7: Observation of zeta potential of nanospray droplets in combination with Melastoma malabathricum and gentamicin

Based on the research, the zeta potential value was- $37.20 \mathrm{mV}$. The nanospray droplets produced from this study had zeta potential according to the requirements. The zeta potential value in the \pm 30 $\mathrm{mV}$ range was a value limit that is able to maintain emulsion stability because a value that was close to neutral reduced the possibility of particles to form aggregates [50]. As a rule of thumb, a zeta potential value of $\pm 30 \mathrm{mV}$ would provide good stability and $\pm 60 \mathrm{mV}$ had very good stability [51]. In the SNEDDS study, the obtained zeta potential value was from -28.8 to $-45.9 \mathrm{mV}$ [48], as well as the SNEDDS study for Pandanus conoideus Lamk in which the value was-54.6 \pm 0.17 . The referring to zeta potential, the surface charge of the droplets would have an effect on the stability of the SNEDDS formulation because the electrostatic repulsion between the droplets prevented the incorporation of the nanoemulsion.

The negative value obtained in the study was due to the presence of surfactants and co-surfactants in the emulsion [45]. Kaseem et al. (2016) showed that the optimized formulations were negatively charged, with values ranging from-15.3 to- $23.9 \mathrm{mV}$, which indicated a stable system and that the emulsion bubbles were well separated $[35,52]$. The presence of electrostatic repulsion between negatively charged droplets prevented the formation of coalescence in nanoemulsions [42]. Non-ionic surfactants produced negatively charged interfaces at neutral $\mathrm{pH}$ due to the differential adsorption of hydroxyl ions $(\mathrm{OH} \sim)$ and hydrated oxonium ions $(\mathrm{H3O}+)$ [53].

\section{Observation of physical stability}

Physical stability was observed visually. Based on the results of the physical stability test, all test samples in the study, namely the nanospray of Melastoma malabathricum and gentamicin fractions and SNEDDS for Melastoma malabathricum and gentamicin fractions, did not experience separation, cracking, or creaming.
Emulsion stability was achieved when surfactant molecules covered the entire oil/water interface, increasing the rheology of the interface, thereby preventing the droplets from joining and causing aggregation with a steric hindrance effect. It is important to determine the minimum amount of surfactant needed to achieve maximum emulsion stability. In other studies, Tween 80 in microemulsion formulations could be used to control oil and deactivate bacteria [54]. The hydrophilicity mechanism of surfactants caused rapid dispersion in the water phase [55].

SNEDDS was able to form nanometer sized and stable emulsions. The separation of the emulsion phase was due to the contact between the droplets caused by Brownian motion and gravity. The rate at which nanospray instability occurred was influenced by the nanospray composition and environmental influences such as oil type, surfactant type, $\mathrm{pH}$, and temperature. The stability of the nanospray could be increased by reducing the size, controlling the droplet size distribution of the dispersion phase, increasing the viscosity of the nanospray, and using additives that act as stabilizers. Physical stability is an important parameter showing that the optimal SNEDDS formula must meet because it describes the durability of a product according to certain limits during storage and use. The optimal formulation that did not show any signs of instability indicates system stability. The SNEDDS system must carry out spontaneous emulsification to form nanoemulsions. The SNEDDS system must be of sufficient quality to withstand the stability to resist creaming, cracking or sedimentation. The selected formulations were subjected to heating-cooling cycles, centrifugation, and exposure to freeze thaw cycles [56].

The stability test used in this study was freeze thaw cycling testing which used high and low storage conditions to increase the speed of drug processing. The commonly used extreme conditions were temperature. High temperatures would accelerate the breakdown of 
active substances [57]. In other studies, all formulations had good stability, that is, no sign of phase separation, turbidity or precipitation in the drug was observed [34]. In another formulation, the ternary phase of the system consisting of Tween 60, Capmul MCM C8 and PEG 400 formed fine nanoemulsion SNEDDS with gentle agitation [42].

The occurrence of clots or deposits marked the breakdown of the nanoemulsion so that the oil was no longer coated with surfactants and co-surfactants. Tween 80 as a non-ionic surfactant was not easily affected by acid and electrolyte conditions, so it remained active as a surface layer between oil and water. A nanoemulsion system was stabilized by ionic surfactants; the surface charge came from the ions that were present in the hydrophilic groups of the surfactants. Ions adsorbed on the droplet surface formed an electric double layer, resulting in a repulsive force between particles that hindered aggregation. In the $\mathrm{o} / \mathrm{w}$ nanoemulsion system containing nonionic surfactants, the surfactants would form a film layer on the droplet surface. The film layer would prevent the droplets from combining in the dispersing medium. The phenomenon of preventing aggregation due to this film was known as steric hindrance [58].

\section{Analysis of transported quercetin on nanospray Melastoma malabathricum Fraction}

The amount of quercetin in nanospray preparations transported through the stratum corneum during a certain time interval can be determined by diffusion tests. Fig. 8 shows the test results.

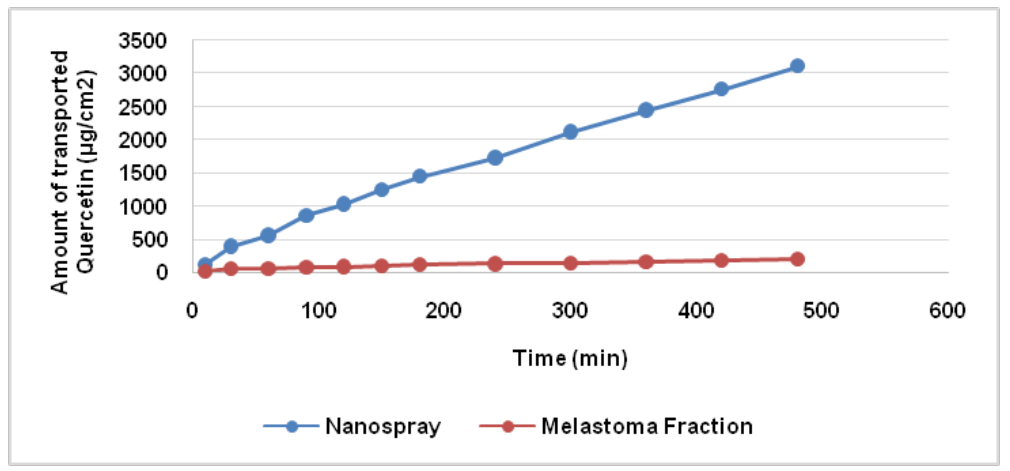

Fig. 8: Amount of quercetin transported on nanospray preparations and Melastoma malabathricum fraction

Based on fig. 8, the amount of quercetin transported on the nanospray of the ethyl acetate fraction for $8 \mathrm{~h}$ was greater than that of ethyl acetate fraction. The EAF without preparation had the smallest amount. This suggests that EAF of Melastoma malabathricum formulated with nanospray could increase the penetration of quercetin through the stratum corneum. The use of skin as an alternative route for drug transport had several advantages over other routes, but administration of drugs by this route was hampered by the low permeability of the outermost layer of the skin, the stratum corneum. Development of several techniques both chemical and physical was to overcome the barrier properties of the stratum corneum. The use of a penetration enhancer that reduces the resistance of the stratum corneum was an effective method [59].

Nanospray formulas could increase absorption and bioavailability because nanoemulsion sized droplets could increase the release of insoluble drugs [60]. Topical absorption routed in carrying drugs and active ingredients into the inner skin layer, in the dermis layer in particular [61]. Formulations using polymers could increase the transport of hydrophobic compounds through the stratum corneum to the deeper layers of the skin, and it increased skin availability [62]. Nanospray ethyl acetate fraction had a greater amount of transported quercetin than Melastoma fraction because it had greater lipid solubility than fraction. The drug had to have sufficiently high lipid solubility to increase drug partition on the lipid membrane [63]. The main challenge in formulation was barrier transport through the skin [64]. Dermatological preparations required a high increase in the effectiveness of drugs on the skin penetrating into the receptor compartment compared to conventional preparations [65]. These preparations increased the penetration of the drug into the skin, and because of their lipid properties, the drug penetrated into the skin layers and kept it for a long time, allowing the drug to be targeted on the skin. Another study of the SNEDDS, using the active compound etravirine (BCS class IV) using labrasol oil: transcutol HP, 6: 1 with a ratio of 2:8, showed the test results meeting the requirements, and in vitro studies illustrated an increase in the dissolution rate [66].

\section{CONCLUSION}

Nanospray can be formulated from optimal SNEDDS using DesignExpert software with a synergistic combination of melastoma and gentamicin. The simplex lattice design method can predict the optimal SNEDDS formula. Nanospray with SNEDDS technology has physical characteristics that meet the requirements and is stable by freeze-thaw cycling testing. In vitro diffusion studies revealed that the release of Melastoma malabathricum from nanospray was faster than without preparation. This research can be developed further regarding the irritation and effectiveness of EAF nanospray to treat antibiotic-resistant diabetic ulcers in animal tests and clinical trials in humans.

\section{ACKNOWLEDGMENT}

Authours acknowledge The Ministry of Research and Technology and the National Invonation Research (BRIN) and Rector of Tanjungpura University Pontianak for providing laboratory facilities.

\section{FUNDING}

Nil

\section{AUTHORS CONTRIBUTIONS}

All the authors have contributed equally.

\section{CONFLICT OF INTERESTS}

The authors declare that no conflict of interest.

\section{REFERENCES}

1. Sarbadhikary, Basu S, Bhowmik S, Datta BK, Mandal NC. Antimicrobial and antioxidant activity of leaf extracts of two indigenous angiosperm species of tripura. Int J Curr Microbiol Appl Sci 2015;4:643-55.

2. Alnajar ZA, Abdulla MA, Ali HM, Alshawsh MA, Hadi AH. Acute toxicity evaluation, antibacterial, antioxidant and immunomodulatory effects of Melastoma malabathricum. Molecules 2012;17:3547-59.

3. Diris AM, Basri F, Metali N, Ahmad H, Taha. Phytochemicals and antimicrobial activities of Melastoma malabathricum and Melastoma beccarianum leaf crude extracts. Res J Phytochem 2017;11:35-41.

4. Devi AS, Rajkumar J, Modilal MR, Ilayaraja R. Antimicrobial activities of Avicennia marina, Caesalpinia pulcherrima and 
Melastoma malabathricum against clinical pathogens isolated from UTI. Int J Pharma Bio Sci 2012;3:698-705.

5. Rajenderan MT. Ethno medicinal uses and antimicrobial properties of Melastoma malabathricum. SEGi Rev 2010;3:34-44.

6. Date AA, Neha D, Rahul D, Mangal N. Self-nanoemulsifying drug delivery system: formulation insights applications and advances. Nanomedicine 2010;5:1596-616.

7. Alwadei M, Kazi M, Alanazi FK. Novel oral dosage regimen based on self-nanoemulsifying drug delivery systems for codelivery of phytochemicals-curcumin and thymoquinone. Saudi Pharm J 2019;27:866-76.

8. Dokania S, Amita KJ. Self-microemulsifying drug delivery system (SMEDDS)-challanges and road ahead. Drug Delivery 2015;22:675-90.

9. Zhao Y, Changguang W, Albert HL, Ke R, Tao G, Zhirong Z, et al. Self-nanoemulsifying drug delivery system (SNEDDS) for oral delivery of Zedoary essential oil: formulation and bioavability studies. Int J Pharm 2010;383:170-7.

10. Baloch J, Sohail MF, Sarwar HS, Kiani MH, Khan GM, Jahan S, et al. Self-nanoemulsifying drug delivery system (SNEDDS) for improved oral bioavailability of chlorpromazine: in vitro and in vivo evaluation. Medicina 2019;55:210.

11. Verma R, Kaushik D. Design and optimization of candesartan loaded self-nanoemulsifying drug delivery system for improving its dissolution rate and pharmacodynamic potential. Drug Delivery 2020;27:756-71.

12. Alsulays S, Imam S, Hussain H, Alyousef A, Altamimi M, Alsulays $\mathrm{B}$, et al. Flufenamic acid-loaded self-nanoemulsifying drug delivery system for oral delivery: from formulation statistical optimization to preclinical anti-inflammatory assessment. J Oleo Sci 2020;69:1257-71.

13. Kontogiannidou E, Meikopoulos M, Gika H, Panteris E, Vizirianakis I, Müllertz A, et al. In vitro evaluation of self-nanoemulsifying drug delivery systems (SNEDDS) containing room temperature ionic liquids (RTILs) for the oral delivery of amphotericin b. Pharmaceutics 2020;12:699.

14. Patel J, Kevin G, Patel A, Raval M, Sheth N. Design and development of a self-nanoemulsifying drug delivery system for telmisartan for oral drug delivery. IJPPS 2011;1:112-8.

15. Pratiwi L, Sari R, Apridamayanti P. Self-nanoemulsifying drug delivery system (SNEDDS) with enhanched solubilization of ethanol extract from mangosteen peels (Garcinia mangostana L.) for treatment of topical gangrene foot: design and optimization. IJDDT 2017;7:314-9.

16. Senapati PC, Sahoo SK, Sahu AN. Mixed surfactant based (SNEDDS) self-nanoemulsifying drug delivery system presenting efavirenz for enhancement of oral bioavailability. Biomed Pharmacother 2016;80:42-51.

17. Tranggono R, Fatma L. Cosmetic science handbook. Jakarta, Indonesia: Gramedia Pustaka Utama; 2007.

18. Mustika A, Fatimah N, Sari GM. Formulation and characterizations of self-nanoemulsifying drug delivery system of extract Petiveria Alliacea (Singawalang) leaves. Int J Appl Pharm 2019;11:61-5.

19. Vilas P, Gujarathi N, Bhushan R. Preparation and in vitro evaluation of self-nanoemulsifying drug delivery system (SNEDDS) containing clopidogrel. Int J Pharm Sci Rev Res 2014;25:10-5.

20. Parmar N, Singla N, Amin S, Kohli K. Study of cosurfactant effect on nanoemulsifying area and development of lercanidipine loaded (SNEDDS) self nanoemulsifying drug delivery system. Colloids Surf B 2011;86:327-38.

21. Beg S, Jena SS, Patra CN, Rizean M, Swain S, Sruti J, et al. Development of solid self-nanoemulsifying granules (SSNEGs) of ondancentron hydrochloride with enhanced bioavailability potential. Colloids Surf B 2013;101:414-23.

22. Eid AM, Baie SH, Arafat OM. The effect of surfactant blends on the production of a novel switeria macrophylla oil selfnanoemulsifying system. Int J Pharm Pharm Sci 2012;46:85-95.

23. Basalious EB, Shawky N, Badr-Eldin SM. SNEDDS containing bioenhancers for improvement of dissolution and oral absorption of lacidipine: development and optimization. Int J Pharm 2010;391:203-11.

24. Sakloetsakun D, Dunnhaupt S, Barthelmes J, Perera G, Bernkop Schnurch A. Combining two technologies: multifunctional polymers and self-nanoemulsifying drug delivery system (SNEDDS) for oral insulin administration. Int J Biol Macromol 2013;61:363-72.

25. Shafiq-un-Nabi S, Shakeel F, Talegaonkar S, Ali J, Baboota S, Ahuja A, et al. Formulation development and optimization using nanoemulsion technique: a technical note. Am Assoc Pharm Sci 2007;8:12-7.

26. Pyka A. Evaluation of the lipophilicity of fat-soluble vitamins. J Planar Chromatography Modern TLC 2009;22:211-5.

27. Singh AP, Gopal L, Khatik, Mishra V, Khurana N, Sharma N, et al. Formulation development and in vitro antioxidant and antidiabetic evaluation of Erioborya Japonica based self nano emulsifying drug delivery system. Int J Appl Pharm 2019;11:313-9.

28. Oza N, Sagar S, Khodakiya A. Use of simplex lattice design in development of oral self-nanoemulsifying drug delivery system containing rosuvastatin calcium. Int J Appl Pharm 2020;12:40-7.

29. Amrutkar C, Salunkhe KS, Chaudhari SR. Review on self nanoemulsifiying drug delivery system. Am J PharmTech Res 2014;4:2249-3387.

30. Nasr A, Gardouh A, Ghonaim H, Abdelghany E, Ghorab M. Effect of oils, surfactants and cosurfactants on phase behaviour and physicochemical properties of self-nanoemulsifying drug delivery system (SNEDDS) for irbesartan and olmesartan. Int J Appl Pharm 2016;8:13-24.

31. Pouton CW, Porter CJ. Formulation of lipid-based delivery systems for oral administration: materials, methods and strategies. Adv Drug Delivery Rev 2008;60:625-37.

32. Constantinides PP, Scalart JP. Formulation and physical characterization of water in oil microemulsion containing long versus medium chain glycerides. Int J Pharm 1997;158:57-68.

33. Gupta RK, Srinivasan MP, Dharmarajan R. Synthesis of short chain thiol capped gold nanoparticles, their stabilization and immobilization on silicon surface. Colloids Surf A 2011;390:149-56.

34. Farooq SU, Kumar S, Shahid AA. Formulation development and evaluation of self-nanoemulsifying drug delivery system of vitamin a for better bioavailability syed. Asian J Pharm 2019;13:9-16.

35. Kassem A, Mohsen AM, Ahmed RS, Essam TM. Selfnanoemulsifying drug delivery sytem (SNEDDS) with enhanced solubilization of nystatin for treatment of oral candidiasis: design, optimization, in vitro and in vivo evaluation. J Mol Liquids 2016;218:219-32.

36. Xi J, Chang Q, Chan CK, Meng ZY, Wang GN, Sun JB, et al. Formulation development and bioavailability evaluation of a self-nanoemulsified drug delivery system of oleanolic acid. Am Assoc Pharm Sci 2009;10:172-82.

37. Fahmy UA, Ahmed OA, Hosny KM. Development and evaluation of avanafil selfnanoemulsifying drug delivery system with rapid onset of action and enhanced bioavailability. AAPS J 2015;16:53-8.

38. Hosny KM, Banjar ZM. The formulation of a nasal nanoemulsion zaleplon in situ gel for the treatment of insomnia. Expert Opinion Drug Delivery 2013;10:1033-41.

39. Singh SK, Verma PR, Razdan B. Glibenclamide-loaded selfnanoemulsifying drug delivery system: development and characterization. Drug Dev Ind Pharm 2010;36:933-45.

40. Fernandez P, Andre V, Rieger J, Kuhnle A. Nanoemulsion formation by emulsion phase inversion. Colloids Surf A 2004;251:53-8

41. Larsen AT, Akesson P, Jureus A, Saaby L, Abu-Rmaileh R, Abrahamsson B, et al. Bioavailability of cinnarizine in dogs: effect of SNEDDS loading level and correlation with cinnarizine solubilization during in vitro lipolysis. Pharm Res 2013;30:3101-13.

42. Badran MM, Taha EI, Tayel MM, Al-Suwayeh SA. Ultra-fine self nanoemulsifying drug delivery system for transdermal delivery of meloxicam: dependency on the type of surfactants. J Mol Liquids 2014;190:16-22.

43. Setiawan SD, Ramadhani CC, Veronika A, Nugroho BH, Syukri Y. Formulation of self nano-emulsifying drug delivery system (SNEDDS) loaded red fruit oil (Pandanus conoideus Lamk.) using biodegradable nutraceutical surfactant. Proceedings of International Conference on Technology and Social Science; 2018. 
44. Dixit AR, Rajput SJ, Patel SG. Preparation and bioavailability assessment of SMEDDS containing valsartan. AAPS J 2010;11:314-21.

45. Yoo JH, Shanmugam S, Thapa P, Lee ES, Balakrishnan P, Baskaran $\mathrm{R}$, et al. Novel self-nanoemulsifying drug delivery system for enhanced solubility and dissolution of lutein. Arch Pharmacal Res 2010;33:417-26.

46. Kanwala T, Kawisha M, Maharjana R, Ghaffara I, Alib HS, Imrana $\mathrm{M}$, et al. Design and development of permeation enhancer containingself-nanoemulsifying drug delivery system (SNEDDS) for ceftriaxonesodium improved oral pharmacokinetics. J Mol Liquids 2019;289:1-9.

47. Patel MJ, Patel N, Patel M. A self-microemulsifying drug delivery system (SNEDDS). Int J Pharm Pharm Sci 2010;4:29-33.

48. Balakumar K, Raghavan CV, Selvan NT, Prasad RH, Abdu S. Self nanoemulsifying drug delivery system (SNEDDS) of rosuvastatin calcium: design, formulation, bioavailability and pharmacokinetic evaluation. Colloids Surf B 2013;112:337-43.

49. Shakeel F, Haq N, Alanazi FK, Alsarra IA. Polymeric solid selfnanoemulsifying drug delivery system of glibenclamide using coffee husk as a low cost biosorbent. Powder Technol 2014;256:352-60.

50. Honary S, Zahir F. Effect of zeta potential on the properties of nano-drug delivery systems-a review (Part 2). Trop J Pharm Res 2013;12:265-73.

51. Wissing SA, Kayser O, Müller RH. Solid lipid nanoparticles for parenteral drug delivery. Adv Drug Delivery Rev 2014;56:1257-72.

52. Agrawal M, Agrawal Y, Itankar P, Patil A, Vyas J, Kelkar A. Phytochemical and HPTLC studies of various extracts of Annona squamosa (Annonaceae). Int J PharmTech Res 2012;4:364-8.

53. Choi KO, Aditya NP, Ko S. Effect of aqueous pH and electrolyte concentration on structure, stability and flow behavior of nonionic surfactant based solid lipid nanoparticles. Food Chem 2014;147:239-44.

54. Alkhatib MA, Aly MM, Rahbeni RA, Balamash KS. Antimicrobial activity of biocompatible microemulsions against Aspergillus niger and herpes simplex virus type 2. Jundishapur J Microbiol 2016;9:374-7.
55. Pouton CW. Lipid formulations for oral administration of drugs: non-emulsifying, self-emulsifying and self-microemulsifying drug delivery systems. Eur J Pharm Sci 2000;11:93-8.

56. Bandyopadhyay S, Katare OP, Singh B. Optimized self nanoemulsifying systems of ezetimibe with enhanced bioavailability potential using long chain and medium chain triglycerides. Colloids Surf B 2012;100:50-61.

57. Sinko JP. Martin's physical pharmacy and pharmaceutical sciences. 5th edition: Lippincott Williams and Wilkins. United State of America; 2006. p. 232-3, 378, 409.

58. Graca M, Bongaerts JH, Stokes JR, Granick S. Friction and adsorption of aqueous polyoxyethylene (Tween) surfactants at hydrophobic surfaces. J Colloid Interface Sci 2007;315:662-70.

59. Songkro S, Wungsintaweekul J, Chartwaingaam S. Investigation of enhancing activity and skin irritation of Zingiber officinale Zingiber cassumunar and Curcuma zedoaria. J Drug Delivery Sci Technol 2008;18:169-79.

60. Villar AM, Naveros BC, Campmany AC, Trenchs MA, Rocabert CB, Bellowa LH. Design and optimization of selfnanoemulsiying drug delivery systems (SNEDDS) for enhanced dissolution of gemfibrozil. Int J Pharm 2012;431:161-75.

61. Scalia S, Trotta V, Iannuccelli V, Bianchi A. Enhancement of in vivo human skin penetration of resveratrol by chitosan-coated lipid microparticles. Colloids Surf B 2015;135:42-9.

62. Smejkalova D, Muthny $T$, Nesporova K, Hermannova $M$, Achbergerova E, Huerta Angeles G, et al. Hyaluronan polymeric micelles for topical drug delivery. Carbohydr Polym 2017;156:86-96.

63. Alvi J, Madan D, Kaushik S, Sardana RS, Pandey A Ali. Comparative study of transfersomes, liposomes, and niosomes for topical delivery of 5-fluorouracil to skin cancer cells: preparation characterization, In vitro release, and cytotoxicity analysis. Anticancer Drugs 2011;22:774-82.

64. Prasanthi DP, Lakshmi. Vesicle-mechanism of transdermal permeation: a review. Asian J Pharm Clin Res 2012;5:18-25.

65. Rahimpour YH, Hamishehkar. Lactose engineering for better performance in dry powder inhalers. Adv Pharm Bull 2012;2:183-7.

66. Preethi GB, Shivakumar HN, Ravikumar M, Swet N. Prototype self emulsifying system of etravirine: design, formulation and in vitro evaluation. Int J Appl Pharm 2018;10:13-9. 